Global COE Hi-Stat Discussion Paper Series 109

$$
\begin{aligned}
& \text { Research Unit for Statistical } \\
& \text { and Empirical Analysis in Social Sciences (Hi-Stat) }
\end{aligned}
$$

\title{
On the Consumption Insurance Effects of Long-term Care Insurance in Japan: Evidence from Micro-level Household Data
}

\author{
Yasushi Iwamoto \\ Miki Kohara \\ Makoto Saito
}

December 2009 


\title{
On the consumption insurance effects of long-term care insurance in
}

\section{Japan: Evidence from micro-level household data*}

\author{
Yasushi Iwamoto, University of Tokyo** \\ Miki Kohara, Osaka University \\ Makoto Saito, Hitotsubashi University
}

December 2009

\begin{abstract}
Using micro-level household data in the 2001 Comprehensive Survey of the Living Conditions of the People on Health and Welfare compiled by the Japanese Ministry of Health, Labor and Welfare, this paper examines how having a household member in need of long-term nursing care can result in welfare losses measured in terms of consumption. In so doing, this study evaluates the role of the public long-term care insurance scheme implemented in Japan in April 2000. The results indicate that when households include a disabled family member, household consumption net of long-term care costs do not decrease as much as before the introduction of long-term care insurance. Further, when compared with the surveys conducted in 1998, the adverse effects on consumption net of long-term care costs have become much weaker. These findings suggest that the introduction of social insurance in 2000 helped Japanese households to reduce the welfare losses associated with a disabled family member.
\end{abstract}

JEL classification numbers: E21, I18

Keywords: social insurance; consumption insurance; long-term care insurance

\footnotetext{
${ }^{*}$ The authors would like to thank the editor for his constructive suggestions. They also acknowledge helpful comments by Dae Il Kim and Yasuyuki Sawada, workshop participants at the Institute of Statistical Research and Seoul National University, and conference attendees at the autumn 2007 meeting of the Japanese Economic Association. International Collaboration Projects of the Economic and Social Research Institute at the Cabinet Office, Japan, supported this research. The authors accessed the micro-level data in the Comprehensive Survey of the Living Conditions of the People on Health and Welfare with special permission of the Statistical Bureau of the Ministry of Internal Affairs and Communications. Regrettably, Japanese statistics law does not permit the authors to disclose details of the dataset.

** Correspondence to: Yasushi Iwamoto, Graduate School of Economics, University of Tokyo, 7-3-1, Hongo, Bunkyo-ku, Tokyo, 113-0033, Japan, E-mail: iwamoto@e.utokyo.ac.jp, phone: +81-3-5841-5641, fax: +81-3-5841-5521.
} 


\section{Introduction}

Employing a micro-level household dataset compiled by the Japanese Ministry of Health, Labor and Welfare, this paper examines how having a household member needing long-term nursing care could result in welfare losses (measured in terms of consumption), and evaluates the role of the public long-term care (hereafter, LTC) insurance implemented in Japan in April 2000.

This paper attempts to measure the welfare loss that a household could suffer from having a disabled or bedridden household member in terms of the effects on household consumption. There are two basic channels whereby a household member in need of long-term nursing care could potentially affect household consumption; first, a reduction in permanent income from the sacrifice of earnings opportunities to care for a disabled family member, and second, a decrease in household consumption net of LTC costs because of expenditure on uninsured costs associated with a disabled family member.

The first channel works as follows. A person who cares for a disabled family member at home may sacrifice a job opportunity. For example, a person who lives with a bedridden parent may give up a position that may require them to move to a different location, or reduce their working hours. In any case, the long-term losses in earnings opportunities could certainly decrease permanent household income. In turn, the decline in permanent income lowers household consumption. The second channel is that without an appropriate insurance instrument, household members are obliged to sacrifice items of consumption (on goods and services) or withdraw their savings to pay for uninsured LTC costs.

The above framework has a similar spirit to the literature on consumption insurance that examines the effect of adverse health shocks on consumption. Based on the Panel Study of Income Dynamics, Cochrane (1991) found that a loss of work hours from health problems reduced food consumption. For example, if a household head was absent from the workplace for more than 100 days (the probability of this event was $7.2 \%$ in the sample), consumption declined by between $11 \%$ and $14 \%$. Using $1975-$ 1985 panel data on families in rural areas in India, Townsend (1994) found that the number of days in the year when an adult male was sick had no impact on consumption. Gertler and Gruber (2002) examined panel data collected in Indonesia and found that 
the impairment of the activities of daily living (ADL) led to a significant economic loss, whereby the impairment of basic ADL ( $2 \%$ in the sample) decreased consumption by $59 \%$ while the impairment of intermediate ADL (24\% in the sample) decreased consumption by $14 \%$. Gertler et al. (2001) used a different dataset on Indonesian households, but obtained a similar result. Dercon and Krishnan (2000) regarded individual nutritional status (weight divided by squared height) as a proxy for consumption, and explored rural Ethiopian household data. They found that nutrition was unaffected by the unpredictable loss of working days.

In contrast, Wagstaff (2007) used the same index as an indicator of health status. Using panel data on Vietnamese households, Wagstaff (2007) found that a decrease in the average nutritional status of household members by one standard deviation reduced food consumption by $1.2 \%$ and non-food consumption by $2.9 \%{ }^{1}$ Finally, using microlevel data from a Japanese household survey conducted before the introduction of public LTC insurance, our earlier work (Iwamoto et al., 2001) found that a disabled household member leads to about a $25 \%$ reduction in household consumption, a loss apparently not covered by formal or informal insurance.

Our empirical investigation takes into consideration the introduction of the public LTC insurance scheme in April 2000. ${ }^{2}$ The Japanese Government introduced this system as compensation for the lack of private insurance. ${ }^{3}$ The public LTC insurance

1 Most studies of consumption insurance have used household data in developing countries. However, Chetty and Looney (2007) caution that the welfare consequences of consumption smoothing may differ between developing and developed countries. Using panel data on households in Indonesia and the US, they found that Indonesian households used relatively costly methods to smooth consumption. Even when households smooth consumption with the limited financial instruments available in developing countries, households may still suffer from adverse shocks, and the provision of social insurance may help to improve welfare substantially. As an alternative approach, using US micro-level data (the National Long-Term Care Survey), Sloan, Hoerger, and Picone (1996) examined the effects of LTC needs on non-housing wealth rather than consumption, and found negative, though less-significant, wealth impacts.

${ }^{2}$ See Campbell and Ikegami (2002) and Mitchell, Piggott, and Shimizutani (2004) for a detailed explanation of Japanese LTC insurance. Geraedts, Heller, and Harrington (2000) carefully document the German social insurance approach to LTC services.

${ }^{3}$ Several studies, including Pauly (1990), Cutler (1993) and Cochrane (1995), have provided a number of explanations for why private insurance fails to cover the risk of LTC [see Norton (2000) for a detailed review]. For example, in respect to the supply- 
scheme aims to provide disabled family members with financial assistance as follows. To start with, enrollees in the public LTC insurance scheme are all residents aged 40 years or more. Each municipal government is responsible for operating the public LTC insurance scheme in its own territory. To obtain benefits, a person has to be examined concerning the status of disability by an expert committee. The government sets the categorization procedure based on various kinds of information. When a person is certified as being in need of LTC services, an independent care manager then develops a service plan for them.

The introduction of the public LTC insurance scheme changed the way that LTC services are delivered and financed in Japan. ${ }^{4}$ As these services had hitherto been financed by municipal governments' general budgets, the supply of services tended to be limited. ${ }^{5}$ The public LTC insurance scheme covers long-term nursing care both at

side, it is extremely difficult to calculate the expenses associated with long-term nursing care. It is also difficult to forecast properly future technical innovation in medical technology. On the demand side, it is difficult for individuals to evaluate their own risk of the need for LTC. Further, individuals who underestimate this necessity have less incentive to buy insurance. They may also substitute the informal care provided by household members for the purchase of insurance. When the demand for insurance is not strong for these and other reasons, a private insurance company would not offer any plan at a reasonable price. Mellor (2001), Finkelstein, McGarry, and Sufi (2005) and Brown and Finkelstein (2007) empirically test some of these theoretical implications.

${ }^{4}$ The coinsurance rule in public LTC insurance is that a beneficiary pays 10 percent of the total costs. Insurance premiums finance one-half of all insurance benefits. The premiums paid by those aged 65 years and over are withheld (in principle) from public pension benefits, while persons aged under 65 years pay premiums along with their health insurance. The premiums of employees are proportional to their earnings. The premiums for persons other than employees are divided into proportional and fixed parts where the former is partly related to income and partly to asset holdings. At the aggregate level, the remaining share of benefits is financed with subsidies from national, prefectural, and municipal governments.

${ }^{5}$ Municipal governments (major or ordinance-designated cities, ordinary cities, towns and villages) offered their own long-term nursing assistance for the disabled elderly even before the central government introduced LTC insurance in 2000. Accordingly, there were substantial regional differences in the extent to which a municipal government provided long-term nursing assistance; some municipal governments offered generous assistance for the disabled, while other local governments did not. At first, it appears that we could exploit this information to identify the institutional effects on consumption insurance. However, as described later, the inability to access any detailed information concerning examinees' places of residence for privacy reasons prevented us from exploiting regional differences in public assistance availability. 
home and in nursing care facilities. Under the public LTC insurance scheme, the services are provided through a quasi-market mechanism. Once a person is certified as needing LTC services, he/she can purchase the necessary services with the help of LTC insurance and freely choose a provider. Because profit-making organizations are permitted to enter homecare markets, the number of LTC service providers has dramatically expanded.

Thus, the extent to which the public LTC insurance scheme can absorb the household risk associated with severely disabled family members-who largely had not been sufficiently insured prior to its introduction—should be subject to a rigorous empirical study. To the best of our knowledge, few studies empirically examine the possible effects of public LTC insurance, although several countries have already introduced similar schemes. ${ }^{6}$ Our paper attempts to offer a rigorous empirical assessment of the public LTC insurance scheme introduced in Japan. Such empirical evidence may then be informative for other countries considering this kind of social insurance.

Because of our focus on the effects of household consumption as a welfare measure, we can evaluate the impact of the introduction of this type of social insurance more precisely. For example, social insurance is expected to absorb the risk of LTC needs. Conversely, as the public LTC insurance scheme does not provide income support, the loss of earnings opportunity may not be covered. Hence, the public LTC insurance scheme differs sharply from other social insurance programs designed to insure income risks more directly. ${ }^{7}$ To highlight this aspect of the public LTC insurance scheme, we carefully separate the effects of having a severely disabled member on household permanent income from the effect on household consumption. In our empirical framework, if the social insurance scheme absorbs the risk of LTC needs, its effect on consumption is not statistically significant after controlling for permanent income. ${ }^{8}$ If

6 Gupta and Li (2004) simulated the optimal plan of purchasing long-term care insurance.

7 Bloemen and Stancanelli (2005) and Gruber (1997) assessed the consumption insurance effects of unemployment insurance.

${ }^{8}$ Wagstaff (2007) found that a health shock had a negative effect on non-medical consumption, even among households that purchased health insurance, and conjectured that health insurance did not effectively tackle income losses. However, Wagstaff (2007) did not take into consideration the possible impact of a health condition on permanent income. 
the effect on consumption is significant before the introduction of the public LTC insurance scheme but insignificant afterwards, then social insurance covers an important risk not covered by the private sector.

The dataset we use is the micro-level data in the Comprehensive Survey of the Living Conditions of the People on Health and Welfare (Kokumin Seikatsu Kiso Chosa in Japanese) (hereafter Survey of Living Conditions or SLC), which is a nationally representative household survey. The SLC provides detailed information about LTC needs and economic status every three years. As the public LTC insurance scheme was introduced in April 2000, we use the datasets gathered before and after this event (namely, 1998 and 2001). Because the introduction of the public LTC insurance scheme was a nationwide policy change, it is rather difficult to distinguish the effect of the LTC insurance from time-series changes in other factors. Public LTC insurance has dramatically changed the environment surrounding the disabled elderly. If any significant change is detected, it is likely to be the effect of public LTC insurance.

The remainder of this paper is organized as follows. Section 2 describes our dataset, while Section 3 reports the estimation results and discusses the implications. Section 4 offers some concluding remarks.

\section{Data descriptions and basic statistics}

\subsection{Data characteristics}

We use the household micro-level data of the Comprehensive Survey of the Living Conditions of the People on Health and Welfare compiled by the Ministry of Health, Labor and Welfare, and recognized as one of the most comprehensive governmentsponsored collections of household micro-level data. The SLC conducts a large-scale survey every three years, when more than 30,000 households typically provide information concerning household income and consumption together with details of the health condition of household members. In the SLC, demographic and health conditions are surveyed in June, while economic conditions, including household income and financial assets, are surveyed in July. For estimation purposes, we employ the surveys conducted in 1998 and 2001.

The SLC is well suited to the purposes of our empirical investigation. First, this large-scale household survey reports on several important dimensions of household 
characteristics, including family structure, job status, income, financial assets, real estate holdings, and health conditions of every family member. In terms of severe health conditions, the SLC surveys in detail whether a family member needs LTC because of a physical disability, and if so, what kind of care is provided. Second, given that it is a large-scale household survey, we can include a reasonable number of households with a member in need of LTC in our sample, even though the probability of a severely disabled family member is extremely low in the population. In this regard, unlike microlevel datasets that survey only those households with disabled members, a dataset constructed from the SLC allows us to explore differences in household behavior between families with disabled members and those without. Third, the 1998 and 2001 surveys are conveniently timed for evaluating the possible welfare impacts of the public LTC insurance scheme introduced in April 2000. ${ }^{9}$

For privacy reasons, we were not permitted to access any detailed information concerning the location of the respondent's residence. We could, however, obtain the prefecture where the surveyed household resided, and the population class of the city, town, or village of residence (150,000 persons or more, between 50,000 and 150,000, and 50,000 or less). Consequently, we cannot exploit the substantial differences in the availability of social services observed among municipal governments before the introduction of the public LTC insurance scheme in 2000.

Both the 1998 and 2001 SLC identified a particular family member residing at home as in need of LTC when he/she required nursing assistance for the following six activities of daily living (ADL): (1) washing face and teeth, (2) changing clothes, (3) eating, (4) discharging, (5) bathing, and (6) walking. Thus, the degree of need for LTC may be measured in terms of how many activities required nursing assistance. In addition, the 1998 SLC classified the state of a bedridden family member according to frequency, from 'occasionally' through 'sometimes' and 'most of the time' to 'completely.' In addition, the 2001 SLC compiles the degree of need of LTC that is authorized under the public LTC insurance scheme law, where an independent examiner judges the state of nursing care required, ranging from Level 1 (the least serious) through to Level 5 (the most serious) by visiting each applicant for a public LTC

\footnotetext{
${ }^{9}$ Iwamoto et al. (2001) used the SLC conducted in 1995. The present paper follows the empirical strategy employed there.
} 
insurance scheme payout. Under this classification, a member classified as Level 5 is nearly equivalent to bedridden.

We construct two kinds of dummy variables concerning the state of disability. One dummy variable takes a value of one if a family member older than 40 years needs help with at least four activities, zero otherwise. The other dummy variable takes a value of one if he/she is bedridden, zero otherwise. We define a bedridden member as one assigned to either of the two most severe states.

The SLC reports the annual household income of the previous year, the monthly expenditure on household consumption in May of the surveyed year, and the health condition of family members as at the first Thursday in June of the surveyed year. For example, the 2001 SLC reports annual income in 2000, monthly consumption expenditure in May 2001, and the health conditions of family members as at June 7, 2001.

One potential problem associated with the timing of the survey is that each household reports its income not in the surveyed year, but in the previous year. To deal with this issue, we construct a dummy variable for currently bedridden members for each household, and a dummy variable for having had bedridden members for more than one year. However, it is not possible to provide such a control when constructing dummy variables for having disabled members in need of at least four activities (the definition of which is described below). In this regard, our estimation potentially fails to capture the effects of disabled members on household income. Nevertheless, this aspect does not affect the estimation results because there is no substantial difference in the estimation results using currently bedridden members and those for one year before. ${ }^{10}$ For this reason, we report the estimation results based on the current state of disabled family members.

${ }^{10}$ More precisely, the point estimates of the dummy variables associated with disabled members in the latter become smaller in absolute terms. Note, however, that the standard errors of the estimates in the latter become larger because of the smaller sample size. Consequently, there is no statistically significant difference between the estimates. Our finding that the impact on income and consumption is stronger among those disabled more recently may indicate that the state of disability tends to grow more serious quickly. 
The SLC also identifies a particular family member who is institutionalized, such as in a nursing facility. ${ }^{11}$ However, neither of the SLCs reports the health condition of institutionalized family members. We construct a dummy variable for the presence of family members who are in nursing facilities in order to capture the close similarity between those nursed at home and the institutionalized.

As discussed in the introduction, we evaluate the welfare impact of a family member in need of LTC in terms of the loss in household consumption. When a disability shock hits a family member, the financing of the extra expenses incurred in caring for the disabled member may be from household savings or compensated for by giving up other consumption expenses. Some family members, particularly the spouse of the household head, may quit their current high-income job and switch to another job with a lower commitment, thereby sacrificing lifetime income and allocating time to the care of the disabled member at home. The combined effects of these compensating activities are eventually reflected in changes in household consumption net of LTC costs. The SLC also reports any uninsured expenses on LTC including extra clothes, beds, caring equipment, charged care service, and uninsured medical expenses. We thus use household consumption net of expenditure on LTC costs as a household welfare measure.

\subsection{Basic statistics}

We only use the sample of households whose household head (more precisely, the highest income earner in the household) is an employee. The reason for this sampleselection procedure is that we are primarily interested in the case where healthier (and maybe younger) household members support an elderly member in need of nursing care. ${ }^{12}$ We also exclude as outliers those whose household income and consumption lie outside the "four standard deviations from the mean" range. The original household sample size is 30,506 for the 1998 SLC and 30,386 for the 2001 SLC. Following our

\footnotetext{
${ }^{11}$ The SLC also identifies family members hospitalized for a long period, but it does not record their age. It is thus impossible to construct a dummy variable for the presence of hospitalized elderly members.

12 Our investigation may underestimate the welfare impact of a disabled member because our sample excludes the more serious case where the household head becomes in need of nursing care.
} 
selection process, the numbers of observations become 15,262 for 1998 and 15,542 for 2001.

Tables 1 and 2 report the basic statistics for our sample comprising the 1998 and 2001 SLC. With regard to the 1998 SLC, the number of households with members in need of nursing care for at least four disability activities is 215 (1.41\%), while the number of households with bedridden members is 101 (0.66\%). For the 2001 SLC, the number of households with members in need of nursing care for at least four disability activities is 419 (2.70\%). Based on the authorized degree of LTC required under the law governing the public LTC insurance scheme, the number of households with members in need of nursing care is 152 (0.98\%) for Level 5 (equivalent to a bedridden state).

Given the differences in the share of families with disabled members between the 1998 and 2001 surveys, it may be difficult to compare the estimations from the 1998 survey with those from the 2001 survey. One possible reason is that in response to the introduction of the public LTC insurance scheme in 2000, greater recognition may have been given to the situation of disabled members within households, and consequently the 2001 survey may have recognized disabled members much more broadly than the 1998 survey.

In both the 1998 and 2001 SLC, a family where an adult child supports his/her disabled parents comprises the largest share of households with disabled members. For example, in the 1998 (2001) SLC, the proportion of households in which a spouse's bedridden parent is supported is $44.6 \%$ (30.3\%), the proportion of households in which a head's bedridden parent is supported is $15.8 \%$ (25.0\%), and the proportion of households in which a bedridden spouse is supported is $24.8 \%$ (27.6\%). The number of households that have disabled members at nursing facilities is $46(0.30 \%)$ in the 1998 SLC, and 93 (0.60\%) in the 2001 SLC.

Table 2 compares the means of representative household characteristics, including income and consumption net of LTC costs, in households with disabled members and those without. According to this table, the average income (or consumption) of the former is not necessarily inferior to that of the latter. As far as the average level is concerned, there is no direct evidence for the adverse impact of a disabled member in terms of household income and consumption. However, note that in families with disabled members, the age of the household head is more than ten years older than in 
families without a disabled member. This finding appears reasonable in that parents of household heads and their spouses are more likely to need LTC when they get older. The numbers of household members and workers are also larger in families with disabled members than in those without. Importantly, these household characteristics may heavily influence household consumption. Section 3 explores in detail how the presence of a disabled member could have welfare impacts after controlling for the other possible effects of household characteristics on income and consumption.

\section{Statistical specification and estimation results}

\subsection{Statistical specification}

Because we include cross-sectional data at particular points in time (1998 and 2001) and not panel data, we cannot estimate a structural form based on dynamic optimization, rather only a reduced-form specification when evaluating the impact of disabled members within a family. If panel data were available, we could control for the fixed effects associated with differences in lifetime income in a precise manner by including growth or the first-order differences of individual consumption. ${ }^{13}$

Given the absence of panel data, however, we must construct a two-stage specification in order to control for the fixed effects. First, we estimate household income as a function of household characteristics assuming fixed effects (by including a dummy variable associated with disabled members), and use predicted household income as a proxy for the permanent income of a household in the second stage. This first-stage estimation allows us to identify the impact of disabled members on household permanent income. In the second-stage estimation, we specify household consumption net of uninsured expenditures on LTC as a function of household characteristics, including the household permanent income predicted by the first-stage estimation, and a dummy variable for the presence of disabled members. For the second-stage estimation, we add as explanatory variables several factors unique to the consumption decision.

\footnotetext{
${ }^{13}$ For example, if relative risk aversion is constant with respect to consumption, then we can remove the Lagrange multiplier associated with an individual budget constraint, which appears as a first-order condition for dynamic optimization, by taking individual consumption growth for different points in time.
} 
There are two channels, indirect and direct, through which disabled household members could yield welfare impacts in terms of consumption net of nursing care costs. Through an indirect channel, a disabled state may reduce household permanent income, thereby lowering consumption. Alternatively, through a direct channel, and given permanent income, consumption may decline through the state of a household having disabled members.

Our two-stage procedure is suitable for classifying the role of insuring risks caused by disabled members. In particular, this procedure allows us to separate the impact of the introduction of public LTC insurance on consumption from the impact on income. As discussed below, with the introduction of LTC insurance, the presence of disabled household members is unlikely to have a direct impact on household consumption, while it may have a more or less direct impact on household income. We are especially interested in whether the direct effect on household consumption disappeared following the introduction of LTC insurance. Structural form regressions are required in this regard.

The LTC insurance scheme provides in-kind benefits for both home and institutional care, but does not provide any cash benefit for the care provided by family members. If the LTC insurance fully covers the needs of LTC services in this way, consumption is affected only through the change in market income. Conversely, if LTC insurance is not available, households suffer from the presence of a disabled member and are obliged to reduce consumption. In the case of the latter, the direct effects may still be present. In sum, the direct effect is likely to disappear with the introduction of LTC insurance, and we thus expect no direct effect. However, it is difficult to determine a priori how the impact on household income may change following the introduction of LTC insurance. Owing to LTC insurance, household members may not have to work harder to purchase LTC services, while they may work more after their release from the provision of care services for their disabled members.

Another important point associated with the income equation is that the estimated coefficient on the presence of disabled members may capture the response of the intensive margin of labor supply more than that of the extensive margin because the list of explanatory variables includes the number of workers in the household. That is, because of LTC insurance, household members do not have to give up their job and can 
keep working, but with reduced hours. In such a case, the negative indirect effect reflects the intensive margin of labor supply.

In the first-stage estimation, we specify the household income function as:

$$
\ln y_{i}=\sum_{j=1}^{J} \alpha_{j} x_{1 i j}+\beta d_{i},
$$

where $y_{i}$ and $x_{1 i j}$ denote the total income and characteristics of household $i$, respectively.

The set of household characteristics $\left\{x_{1 i j}\right\}$ includes the number of household members (in logarithms), the age of the household head (and its square), the sex of the household head, and whether the household head is married or single. It also includes the number of children relative to the number of household members, the number of parents relative to the number of household members, the number of income earners, the scale of the firm where the household head is employed, and a dummy variable for households residing in a city. In addition, we include a dummy variable for the presence of disabled members in nursing facilities to consider the similarity between nursing the disabled member in and outside the home. As mentioned earlier, although the timing of the recording of a health condition differs from the timing of the recording of household income, such differences in recorded timing do not substantially affect the estimation results. We also include $d_{i}$, a dummy variable indicating the presence of disabled members within household $i$. Thus, a coefficient on $d_{i}(\beta)$ represents the (possibly negative) effect of disabled members on permanent income.

In the second-stage estimation, we specify the household consumption function as:

$$
\ln c_{i}=\gamma\left(\ln y_{i}\right)^{e}+\sum_{j=1}^{J} \lambda_{j} x_{2 i j}+\mu d_{i},
$$

where $\left(\ln y_{i}\right)^{e}$ is the household income predicted in the first-stage estimation and $c_{i}$ denotes household consumption net of nursing care costs.

Unlike the first-stage estimation, the SLC records monthly household consumption in May 1998 and May 2001, and there is no significant difference in the timing of the recording of health conditions (in early June) and household consumption. A set of 
household characteristics adds a dummy variable for children attending a college and living separately, and a dummy variable associated with home ownership in order to control for other possible impacts on consumption behavior.

In equation (2) the coefficient on $d_{i}(\mu)$ represents the direct effect of disabled members on household consumption. A possible dynamic effect, such as adjustment costs or habit formation, may be captured by the coefficient on the proxy for permanent income $(\gamma)$ being less than one. Throughout the two-stage estimation procedure, we assert that the state of having disabled members is completely exogenous. Although we regress a dummy variable for disabled members on every possible household characteristic to explore their endogenous nature, we cannot find any systematic pattern in determining the state of having disabled members. ${ }^{14}$ Thus, the identification assumption employed can be justified as far as our dataset is concerned.

\subsection{Estimation results}

Tables 3 and 4 report the estimation results of the income and consumption functions based on equations (1) and (2) using the 1998 and 2001 SLC datasets for both household members with at least four disability activities and bedridden household members. In computing the standard errors, we employ the adjustment proposed by Murphy and Topel (1985) for all of our estimation results.

While our main interest lies in examining the effects of the presence of disabled members on household income and consumption, we briefly explore the effects of other household characteristics. Most of the estimated coefficients appear to be quite reasonable. For example, household income increases with age, but at a diminishing rate, while it increases with the number of household members, but decreases with the number of children. Both households with male and married heads and those working for larger firms or residing in larger cities tend to earn higher incomes. Household consumption largely reflects household income and consumption is influenced by student-related expenditure. A significantly positive coefficient on the dummy variable

\footnotetext{
14 The only exception is that the probability of having disabled members tends to be higher in households with more rooms and/or a larger ground area. This indicates that physical capacity is an important determinant in nursing disabled members at home.
} 
for home ownership indicates that houses that are owned may serve as a proxy for net household wealth.

In terms of the effects of the presence of disabled members, we first discuss the case where household members with at least four disability activities are considered disabled members. As documented in Table 3 for the 1998 SLC dataset, the state of having disabled members decreases household income by 5.5\% for the 1998 SLC, although the estimate is only marginally significant. However, the presence of disabled members has a significantly negative effect on household consumption, reducing it by $9.2 \%$. The estimated marginal propensity to consume out of permanent income, as captured by $\gamma$, is slightly less than $50 \%$ (45.8\%). As suggested earlier, an estimated $\gamma$ less than one may be a consequence of slow consumption adjustment because of habit formation. Thus, because of the combined effect through both indirect and direct channels, household consumption would decline by $11.7 \%$ for households with disabled members.

One point to be noted about consumption functions is that the estimated coefficient on the dummy variable for disabled members in nursing facilities is significantly negative in the 1998 estimation; that is, household consumption declines by $19.6 \%$ in the presence of disabled members in nursing facilities. However, a similar effect is absent from the 2001 survey. We discuss this aspect of the estimation results later.

The estimation results of the 2001 SLC contrast with those of the 1998 SLC in that the state of having disabled members has a significantly negative impact only on household income. As shown in Panel B of Table 3, the state of having a disabled member results in a $22.5 \%$ decrease in household income, while it has little direct impact on household consumption. Consequently, the state of having disabled members reduces household consumption, but only through the indirect channel. Given that we estimated the coefficient on predicted household income to be $41.8 \%$, the state of having disabled members would reduce household consumption by $9.4 \%$.

As shown in Table 4, quite similar results are available in the case where the bedridden are regarded as disabled members. Based on the 1998 SLC, because of the combined effect through both indirect and direct channels, household consumption would decline by $11.8 \%$ for households with disabled members $(11.7 \%$ for the alternative). Based on the 2001 SLC, on the other hand, the state of having disabled 
members reduces household consumption by $6.4 \%$ because of only the indirect effect (9.4\% for the alternative).

The overall impact of the state of having disabled members on household consumption has weakened significantly over time. Household consumption decreases by $11.7 \%$ through the indirect and direct channels in 1998. In contrast, it decreases by only $9.4 \%$ through the indirect channel in 2001. In the case of bedridden members, the combined effects are $-11.8 \%$ in 1998 and $-6.4 \%$ in 2001 . The pattern in diminished impacts of the state of having disabled members can be justified by the introduction of the public LTC insurance scheme law in 2000. This is also consistent with the fact that municipal governments preempted the public LTC system by implementing its provisions before 2000. ${ }^{15}$

Given the above estimation results based on the 1998 and 2001 SLC datasets, we make some remarks on the possible impacts of the public LTC insurance scheme introduced in April 2000. First, the most important result is that a negative effect of disabled household members on consumption is present in the 1998 SLC, but absent in the 2001 SLC. We may interpret this result as supportive evidence for the direct effect of the public LTC insurance scheme. That is, the public LTC insurance could alleviate the adverse effects on consumption among the households with severely disabled members. Second, another relevant result is that the coefficient on the dummy variable for disabled members in nursing facilities is significantly negative in the 1998 SLC, but insignificant in the 2001 SLC. One possible interpretation of this result is that the public insurance system may have reduced the potential burden on even those who would have nursed disabled members outside the home.

Finally, one potentially puzzling result is that the reduction in household income from a disabled member became larger in 2001. However, this could be consistent with

15 The reduced form regression immediately derives the overall effect, but it is not suitable for our purposes to differentiate between the direct and indirect effects. Thus, we would like to focus on the structural form regression. For a robustness check, we ran reduced form regressions. In 1998, consumption falls by $10.8 \%$ for the baseline result and $10.4 \%$ in the case of the dummy for bedridden. Both point estimates are only 1 percentage point smaller than in the structural form estimation. In 2001, consumption falls by $6.4 \%$ for the baseline case and by $1.4 \%$ (statistically insignificant) for the bedridden dummy. The difference becomes larger for the latter case, probably because the reduced form inappropriately incorporates a statistically insignificant direct effect. 
household behavior, as explained in Section 3.1. It may then not necessarily follow from this estimation result that the burden of having disabled members became heavier in terms of income earnings following the introduction of LTC insurance. For example, when the expenses of LTC services were not covered by insurance, the financial needs of households with a disabled member may have forced someone to allocate their time endowment to market labor. In this case, the lower impact on earnings under insufficient insurance may lead to a heavier welfare loss. Another possibility is that as the Japanese LTC insurance financially covers market care services available at home, caregivers may have to reduce work hours to receive nursing services at home. In any case, a more detailed empirical investigation is required on the labor supply mechanism of households with disabled members.

\subsection{Discussion}

As discussed, the state of a household having disabled members has a significantly negative impact on household welfare given the decrease in household consumption in both the 1998 SLC and the 2001 SLC. However, the pattern differs between the two datasets. In the 1998 SLC, the state of having a disabled member has negative impacts on both income and consumption. In the 2001 SLC, on the other hand, the state of having disabled members has negative impacts on income, but not on consumption. As the introduction of the public LTC insurance scheme was a nationwide policy change, a well-designed control group was not available. Therefore, we cannot preclude the possibility that a different consumption insurance effect was caused by time series changes in other factors; for example, the growth of private LTC insurance, the decline in LTC costs through technological progress, or the development of informal insurance markets. However, neither factor is likely to explain the diminished impact on consumption. ${ }^{16}$ The most significant change in the environment surrounding persons needing LTC was the most likely cause.

${ }^{16}$ Although the market for private LTC insurance is still evolving to some extent, its size is nevertheless tiny compared with public LTC insurance, which provided around 4 trillion yen of benefits in 2001. Even after the introduction of public LTC insurance, the out-of-pocket expenditure on LTC services remains non-negligible. As shown in Table 2, households including a member with at least four disabled activities spent 22 thousand yen per month on LTC services in 2001. Although the monthly LTC expenditures 
Our results jointly demonstrate that the introduction of the public LTC insurance scheme in 2000 substantially mitigated the risk faced by a household with a severely disabled member. First, we find that after controlling for the effect of household income, the state of having disabled members still has a significantly negative impact on household consumption in 1998, but little effect on household consumption in 2001. Indeed, the public LTC insurance scheme (specifically designed to mitigate consumption risk) helps to absorb the risk of LTC needs at the level of household consumption.

Second, the estimation results imply that the public LTC insurance scheme reduces the risk faced by a household that has institutionalized a disabled member in a nursing facility. According to the 1998 analysis, disabled members outside the home should cost substantially more; that is, household consumption should decrease by about $20 \%$ when there are family members in nursing facilities. However, such an adverse effect on household consumption is absent from the 2001 estimation results. One possible interpretation of the difference among the three sets of results is that the public insurance system may even help mitigate the potential burden of those with institutionalized disabled members. Under the pre-public LTC insurance scheme era, the provision of institutional nursing services was part of the social welfare program, and the fees for nursing facilities depended on the income level of the user's household. For middle-income earners who had institutionalized their parents in nursing facilities, the out-of-pocket payments were a burden. As the public LTC insurance scheme pays $90 \%$ of total costs, this then helps to reduce the financial burden on middle-income households.

\section{Concluding remarks}

The literature on consumption insurance has successfully revealed the kinds of risks not well absorbed by informal, private, or social insurance. Our paper aimed to connect this approach to a public policy issue by comparing the consumption insurance effects

significantly dropped from the level in 1998, it still represented $7.1 \%$ of total expenditure. It is also unlikely that opportunities for informal insurance have been enhanced in Japanese society. In fact, the proportion of the elderly who live with their adult children has steadily declined. 
given a fundamental change in the social insurance scheme. Employing the micro-level household data in the 1998 and 2001 SLC compiled by the Japanese Ministry of Health, Labor and Welfare, this paper has examined how the state of having a household member who needs LTC results in welfare losses measured in terms of consumption, and evaluates the role of the public LTC insurance scheme introduced in April 2000.

Our findings are summarized as follows. First, in the 1998 SLC, the state of having disabled members has a negative impact on both income and consumption. In the 2001 SLC, on the other hand, the state of having a disabled member has a negative impact on income, but not on consumption. Second, the combination of indirect and direct impacts of LTC needs on household consumption has become weaker over time. Third, even the burden borne by a household with a disabled family member outside the home in 2001 is to some extent reduced.

These findings jointly demonstrate that the social insurance approach to financing LTC costs in Japan has helped reduce the welfare losses associated with a disabled family member. That is, the public LTC insurance scheme successfully absorbs the risk of expenses for a disabled member not covered by the private insurance market. Consequently, even when households have a disabled family member, household consumption net of LTC costs does not decrease as much as before the introduction of the public LTC insurance scheme. 


\section{References}

Brown, J. R., Finkelstein, A., 2007. Why is the market for long-term care insurance so small? Journal of Public Economics 91, 1875-2086.

Campbell, J. C., Ikegami, N., 2000. Long-term care insurance comes to Japan. Health Affairs 19, 26-39.

Chetty, R., Looney, A., 2007. Income risk and the benefits of social insurance: Evidence from Indonesia and the United States. In: Ito, T., Rose, A., (Eds.). Fiscal Policy and Management in East Asia. Chicago: University of Chicago Press, 99121.

Cochrane, J. H., 1991. A simple test of consumption insurance. Journal of Political Economy 99, 957-976.

Cochrane, J. H., 1995. Time-consistent health insurance. Journal of Political Economy 103, 445-473.

Cutler, D., 1993. Why doesn’t the market fully insure long-term care? NBER Working Paper No. 4301.

Dercon, S., Krishnan, P., 2000. In sickness and in health: Risk sharing within households in rural Ethiopia. Journal of Political Economy 108, 688-727.

Finkelstein, A., McGarry, K., Sufi, A., 2005. Dynamic inefficiencies in insurance markets: Evidence from long-term care insurance. American Economic Review 95, 224-228.

Geraedts, M., Heller, G. V., Harrington, C. A., 2000. Germany’s long-term care insurance: Putting a social insurance model into practice. Milbank Quarterly 78, 375-401.

Gertler, P., Gruber, J., 2002. Insuring consumption against illness. American Economic Review 92, 51-76.

Gertler, P., Levine, D. I., Moretti, E., 2001. Do microfinance programs help families insure consumption against illness? mimeo.

Gruber, J., 1997. The consumption smoothing benefits of unemployment insurance. American Economic Review 87, 192-205.

Gupta, A., Li, L., 2004. A modeling framework for optimal long-term care insurance purchase decisions in retirement planning. Health Care Management Science 7, 105-117. 
Iwamoto, Y., Kohara, M., Saito, M., 2001. On the welfare loss of the state of having members in need of long-term care. Kikan Shakai Hosho Kenkyu 36, 547-560. (in Japanese)

Mellor, J. M., 2001. Long-term care and nursing home coverage: Are adult children substitutes for insurance policies? Journal of Health Economics 20, 527-547.

Mitchell, O. S., Piggott, J., Shimizutani, S., 2004. Aged-care support in Japan: Perspectives and challenges. NBER Working Paper No. 10882.

Murphy, K. M., Topel, R. H., 1985. Estimation and inference in two-step econometric models. Journal of Business and Economic Statistics 3, 370-379.

Norton, E. C., 2000. Long-term care. In: Culyer, A. J., Newhouse, J. P. (Eds.). Handbook of Health Economics Volume 1B. Amsterdam: Elsevier, 955-994.

Pauly, M. V., 1990. The rational nonpurchase of long-term-care insurance. Journal of Political Economy 98, 153-168.

Sloan, F. A., Hoerger, T. H., Picone, G., 1996. Effects of strategic behavior and public subsidies on families' savings and long-term care decisions. In: Eisen, R., Sloan, F. (Eds.). Long-term Care: Economic Issues and Policy Solutions. Boston: Kluwer Academic Publishers, 45-78.

Townsend, R. M., 1994. Risk and insurance in village India. Econometrica 62, 171-184.

Wagstaff, A., 2007. The economic consequences of health shocks. Journal of Health Economics 26, 82-100. 
Table 1: Descriptive Statistics of Major Variables

Panel A: 1998 SLC

\begin{tabular}{|c|c|c|c|c|}
\hline \multirow[b]{3}{*}{ logarithmic family consumntion } & \multicolumn{4}{|c|}{ Total Sample Number: 15262} \\
\hline & Average & $\begin{array}{l}\text { Standard } \\
\text { Deviation }\end{array}$ & Minimum & Maximum \\
\hline & 12.4259 & 0.5117 & 9.2103 & 14.4935 \\
\hline logarithmic family disposable income & 6.2683 & 0.6427 & 1.3863 & 7.7717 \\
\hline the number of family members & 1.0491 & 0.5325 & 0 & 2.3026 \\
\hline the age of a household head & 48.2905 & 13.2591 & 18 & 95 \\
\hline a dummy of a male head & 0.8736 & 0.3323 & 0 & 1 \\
\hline a dummy of a married head & 0.7861 & 0.4101 & 0 & 1 \\
\hline the household share of children & 0.1797 & 0.2217 & 0 & 1 \\
\hline a dummy of students & 0.0298 & 0.1701 & 0 & 1 \\
\hline the houshold share of parents & 0.0397 & 0.1081 & 0 & 0.6667 \\
\hline a dummy of persons in nursing facilities & 0.0030 & 0.0548 & 0 & 1 \\
\hline a dummy of firm scale (medium) & 0.1947 & 0.3960 & 0 & 1 \\
\hline a dummy of firm scale (large) & 0.2696 & 0.4437 & 0 & 1 \\
\hline a dummy of firm scale (government office) & 0.0302 & 0.1712 & 0 & 1 \\
\hline a dummy of homeownership & 0.6666 & 0.4714 & 0 & 1 \\
\hline a dummy of city scale (metropolitan) & 0.1909 & 0.3930 & 0 & 1 \\
\hline a dummy of city scale (large) & 0.3156 & 0.4648 & 0 & 1 \\
\hline a dummy of city scale (medium) & 0.2197 & 0.4141 & 0 & 1 \\
\hline a dummy of city scale (small) & 0.0589 & 0.2355 & 0 & 1 \\
\hline the number of workers & 1.6958 & 0.8486 & 1 & 7 \\
\hline $\begin{array}{l}\text { a dummy of household members with at } \\
\text { least four disabled acitivities }\end{array}$ & 0.0141 & 0.1179 & 0 & 1 \\
\hline a dummy of bedridden household members & 0.0066 & 0.0811 & 0 & 1 \\
\hline
\end{tabular}

Panel B: 2001SLC

\begin{tabular}{lrrrr}
\hline & \multicolumn{2}{c}{ Total Sample Number: 15542} & \\
& Average & $\begin{array}{l}\text { Standard } \\
\text { Deviation }\end{array}$ & Minimum & Maximum \\
\cline { 2 - 5 } logarithmic family consumption & 12.4003 & 0.5337 & 9.2103 & 14.3808 \\
logarithmic family disposable income & 6.1899 & 0.7028 & 0 & 7.7511 \\
the number of family members & 1.0840 & 0.5343 & 0 & 2.4849 \\
the age of a household head & 49.7730 & 13.8367 & 18 & 101 \\
a dummy of a male head & 0.8714 & 0.3347 & 0 & 1 \\
a dummy of a married head & 0.7766 & 0.4165 & 0 & 1 \\
the household share of children & 0.1795 & 0.2219 & 0 & 1 \\
a dummy of students & 0.0370 & 0.1888 & 0 & 1 \\
the houshold share of parents & 0.0589 & 0.1298 & 0 & 0.7500 \\
a dummy of persons in nursing facilities & 0.0060 & 0.0771 & 0 & 1 \\
a dummy of firm scale (medium) & 0.1793 & 0.3836 & 0 & 1 \\
a dummy of firm scale (large) & 0.1457 & 0.3529 & 0 & 1 \\
a dummy of firm scale (government office) & 0.1052 & 0.3068 & 0 & 1 \\
a dummy of homeownership & 0.7627 & 0.4254 & 0 & 1 \\
a dummy of city scale (metropolitan) & 0.1375 & 0.3444 & 0 & 1 \\
a dummy of city scale (large) & 0.2718 & 0.4449 & 0 & 1 \\
a dummy of city scale (medium) & 0.2133 & 0.4096 & 0 & 1 \\
a dummy of city scale (small) & 0.0892 & 0.2851 & 0 & 1 \\
the number of workers & 1.8234 & 0.9077 & 1 & 7 \\
a dummy of household members with at & 0.0270 & 0.1620 & 0 & 1 \\
least four disabled acitivities & & & & \\
a dummy of bedridden household members & 0.0098 & 0.0984 & 0 & 1 \\
\hline
\end{tabular}




\section{Table 2: Long Term Care Needs and Family Characteristics}

\section{Panel A: 1998 SLC}

\begin{tabular}{|c|c|c|c|c|c|c|c|c|c|c|}
\hline \multirow{4}{*}{$\begin{array}{l}\text { (total observations: 15262) } \\
\text { (1) monthly household consumption (yen) }\end{array}$} & \multicolumn{5}{|c|}{ household members with at least four disabled members } & \multicolumn{5}{|c|}{ bedridden household members } \\
\hline & \multirow{3}{*}{ Mean } & \multicolumn{2}{|c|}{ without the disabled } & \multicolumn{2}{|c|}{ with the disabled } & \multicolumn{3}{|c|}{ without the disabaled } & \multicolumn{2}{|c|}{ with disabled } \\
\hline & & & (Standard Deviation) & Mean & (Standard Deviation) & Mean & & d Deviation) & Mean & d Deviation) \\
\hline & & 284384.3 & (167656.9) & 348093 & (163677.3) & & 284745.1 & (167578.7) & 365841.6 & (176823.5) \\
\hline (2) monthly expenditure on LTC (yen) & & 174.3 & (3829.1) & 47641.86 & (81134.7) & & 527.7 & (9882.0) & 48158.4 & (63158.2) \\
\hline (1) - (2) & & 284210.0 & (167559.5) & 300451.2 & (144381.0) & & 284217.3 & (167227.3) & 317683.2 & (170008.7) \\
\hline $\begin{array}{l}\text { annual household income (ten thousand } \\
\text { ven) }\end{array}$ & & 625.9 & $(347.3)$ & 753.5 & $(375.0)$ & & 626.7 & $(347.4)$ & 773.7 & $(405.2)$ \\
\hline $\begin{array}{l}\text { ven } \\
\text { the age of a household head }\end{array}$ & & 48.1479 & (13.1955) & 58.2698 & (13.9060) & & 48.2121 & (13.2154) & 60.0594 & (14.5594) \\
\hline the number of household members & & 3.2170 & $(1.4880)$ & 4.6558 & (1.4985) & & 3.2265 & (1.4919) & 4.8515 & $(1.4992)$ \\
\hline the number of children & & 0.7760 & (1.0314) & 0.7535 & (1.0411) & & 0.7760 & (1.0142) & 0.7327 & $(0.9989)$ \\
\hline the number of workers & & 1.6927 & $(0.8473)$ & 1.9116 & $(0.9103)$ & & 1.6936 & $(0.8473)$ & 2.0198 & $(0.9693)$ \\
\hline a dummy of homeownership & & 0.6633 & $(0.4726)$ & 0.9023 & $(0.2976)$ & & 0.6649 & $(0.4720)$ & 0.9208 & $(0.2710)$ \\
\hline a dummy of a male head & & 0.8724 & $(0.3337)$ & 0.9581 & $(0.2007)$ & & 0.8731 & $(0.3329)$ & 0.9505 & $(0.2180)$ \\
\hline a dummy of a married head & & 0.7843 & $(0.4113)$ & 0.9070 & $(0.2911)$ & & 0.7853 & $(0.4106)$ & 0.9010 & $(0.3002)$ \\
\hline a dummy of two-generation family & & 0.1296 & $(0.3355)$ & 0.6279 & $(0.4845)$ & & 0.1329 & $(0.3395)$ & 0.6436 & $(0.4813)$ \\
\hline the household share of children & & 0.1804 & $(0.2229)$ & 0.1309 & $(0.1728)$ & & 0.1800 & $(0.2221)$ & 0.1235 & $(0.1586)$ \\
\hline a dummy of students & & 0.0294 & $(0.1690)$ & 0.0558 & $(0.2301)$ & & 0.0297 & $(0.1697)$ & 0.0495 & $(0.2180)$ \\
\hline a dummy of firm scale (medium) & & 0.1952 & $(0.3964)$ & 0.1581 & $(0.3657)$ & & 0.1949 & $(0.3961)$ & 0.1584 & $(0.3670)$ \\
\hline a dummy of firm scale (large) & & 0.2704 & $(0.4442)$ & 0.2140 & $(0.4111)$ & & 0.2698 & $(0.4439)$ & 0.2376 & $(0.4278)$ \\
\hline a dummy of firm scale (government office) & & 0.0305 & $(0.1720)$ & 0.0093 & $(0.0962)$ & & 0.0303 & $(0.1715)$ & 0.0099 & $(0.0995)$ \\
\hline a dummy of city scale (metropolitan) & & 0.1911 & $(0.3932)$ & 0.1721 & $(0.3783)$ & & 0.1909 & $(0.3930)$ & 0.1881 & $(0.3928)$ \\
\hline a dummy of city scale (large) & & 0.3166 & $(0.4652)$ & 0.2465 & $(0.4320)$ & & 0.3164 & $(0.4651)$ & 0.1980 & $(0.4005)$ \\
\hline a dummy of city scale (medium) & & 0.2204 & $(0.4145)$ & 0.1721 & $(0.3783)$ & & 0.2198 & $(0.4142)$ & 0.1980 & $(0.4005)$ \\
\hline a dummy of city scale (small) & & 0.0586 & $(0.2349)$ & 0.0791 & $(0.2705)$ & & 0.0588 & $(0.2353)$ & 0.0693 & $(0.2552)$ \\
\hline
\end{tabular}




\section{Panel B: 2001SLC}

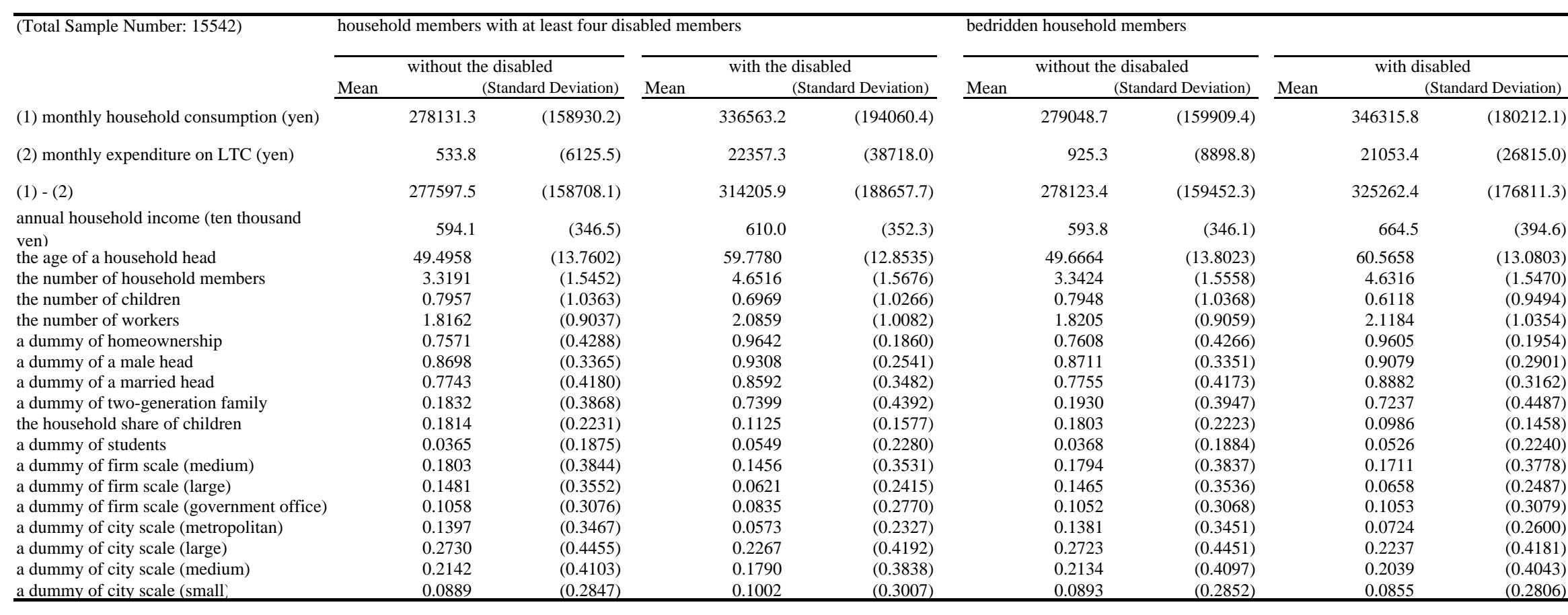


Table 3: Estimation Results with a Dummy for Having at Least Four Disabled Activities

Panel A: the 1998 SLC

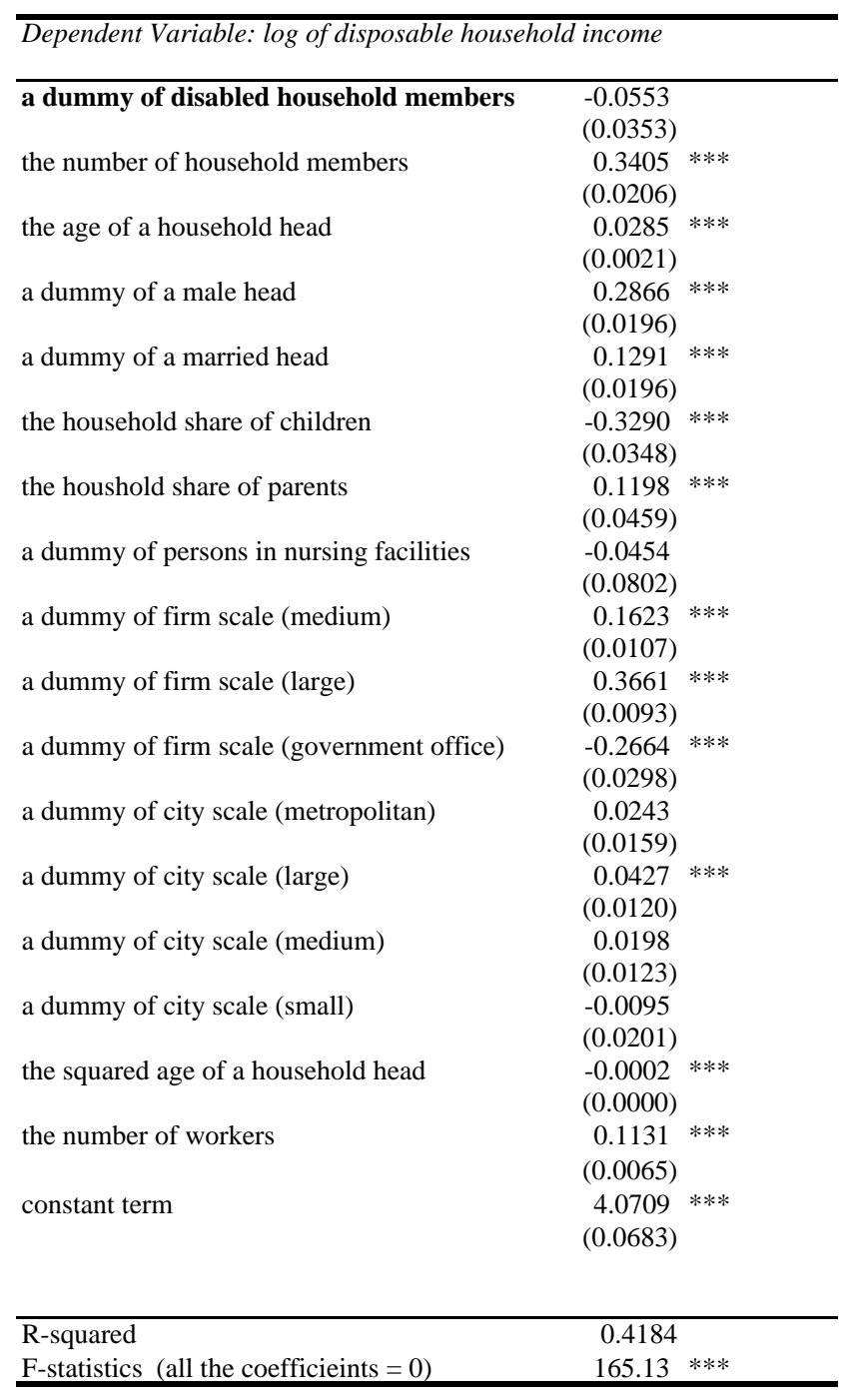

\begin{tabular}{|c|c|}
\hline a dummy of disabled household members & $\begin{array}{l}-0.09166^{* * *} \\
(0.0311)\end{array}$ \\
\hline the predicted Income & $\begin{array}{l}0.4577 \text { *** } \\
(0.0295)\end{array}$ \\
\hline the number of household members & $\begin{array}{l}0.0741 \\
(0.0201)\end{array}$ \\
\hline the age of a household head & $\begin{array}{l}0.0025 \\
(0.0004)\end{array}$ \\
\hline a dummy of a male head & $\begin{array}{l}-0.0705 * * * \\
(0.0164)\end{array}$ \\
\hline a dummy of a married head & $\begin{array}{c}0.1065 \\
(0.0145)\end{array}$ \\
\hline the household share of children & $\begin{array}{l}0.1845 \text { *** } \\
(0.0315)\end{array}$ \\
\hline a dummy of students & $\begin{array}{c}0.3422 \\
(0.0211)\end{array}$ \\
\hline the houshold share of parents & $\begin{array}{l}-0.0541 \\
(0.0386)\end{array}$ \\
\hline a dummy of persons in nursing facilities & $\begin{array}{l}-0.1964 \\
(0.0652)\end{array}$ \\
\hline a dummy of firm scale (medium) & $\begin{array}{l}-0.0133 \\
(0.0112)\end{array}$ \\
\hline a dummy of firm scale (large) & $\begin{array}{l}-0.0500 * * * \\
(0.0147)\end{array}$ \\
\hline a dummy of firm scale (government office) & $\begin{array}{c}0.0759 \\
(0.0227)\end{array}$ \\
\hline a dummy of homeownership & $\begin{array}{l}0.0405 \\
(0.0093)\end{array}$ \\
\hline a dummy of city scale (metropolitan) & $\begin{array}{l}0.1728 \text { *** } \\
(0.0118)\end{array}$ \\
\hline a dummy of city scale (large) & $\begin{array}{l}0.1128 \\
(0.0104)\end{array}$ \\
\hline a dummy of city scale (medium) & $\begin{array}{l}0.0851 \text { *** } \\
(0.011)\end{array}$ \\
\hline a dummy of city scale (small) & $\begin{array}{c}0.0085 \\
(0.0166)\end{array}$ \\
\hline constant term & $\begin{array}{l}9.1946 \quad * * * \\
(0.1485)\end{array}$ \\
\hline$\overline{\text { F-statistics (all the coefficients }=0 \text { ) }}$ & $332.28 * * *$ \\
\hline
\end{tabular}




\section{Panel B: the 2001 SLC}

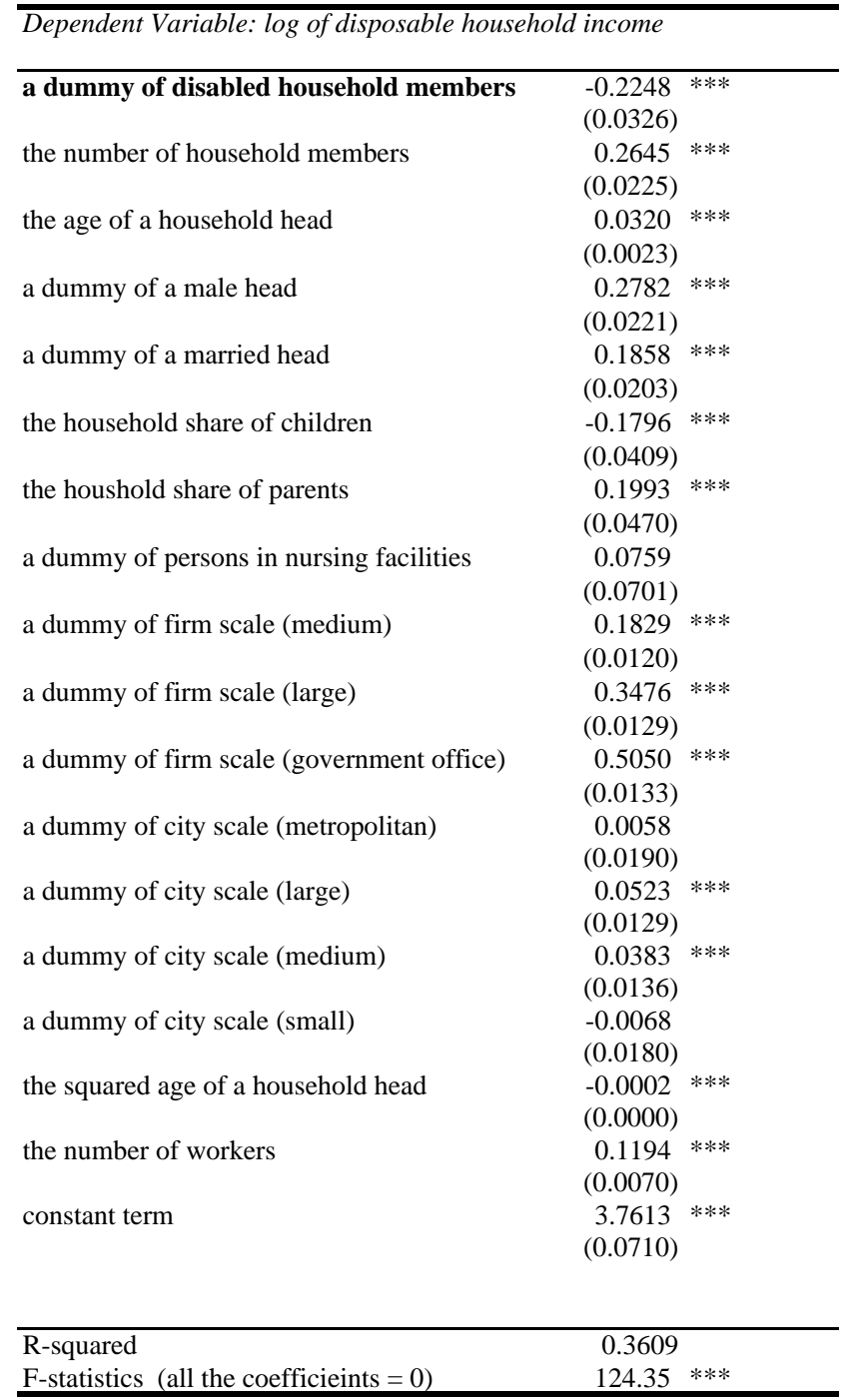

\begin{tabular}{|c|c|c|}
\hline a dummy of disabled household members & $\begin{array}{l}0.0295 \\
(0.025)\end{array}$ & \\
\hline the predicted Income & $\begin{array}{c}0.4181 \\
(0.0273)\end{array}$ & $* * *$ \\
\hline the number of household members & $\begin{array}{c}0.1072 \\
(0.0184)\end{array}$ & $* * *$ \\
\hline the age of a household head & $\begin{array}{c}0.0015 \\
(0.0004)\end{array}$ & $* * *$ \\
\hline a dummy of a male head & $\begin{array}{c}-0.0543 \\
(0.0167)\end{array}$ & *** \\
\hline a dummy of a married head & $\begin{array}{c}0.0983 \\
(0.0152)\end{array}$ & $* * *$ \\
\hline the household share of children & $\begin{array}{c}0.1436 \\
(0.0304)\end{array}$ & $* * *$ \\
\hline a dummy of students & $\begin{array}{c}0.3384 \\
(0.0199)\end{array}$ & $* * *$ \\
\hline the houshold share of parents & $\begin{array}{l}0.0518 \\
(0.035)\end{array}$ & \\
\hline a dummy of persons in nursing facilities & $\begin{array}{c}0.0187 \\
(0.0485)\end{array}$ & \\
\hline a dummy of firm scale (medium) & $\begin{array}{l}-0.0230 \\
(0.0118)\end{array}$ & $* *$ \\
\hline a dummy of firm scale (large) & $\begin{array}{l}-0.0388 \\
(0.0154)\end{array}$ & $* * *$ \\
\hline a dummy of firm scale (government office) & $\begin{array}{l}-0.0714 \\
(0.0189)\end{array}$ & $* * *$ \\
\hline a dummy of homeownership & $\begin{array}{c}0.0795 \\
(0.0105)\end{array}$ & *** \\
\hline a dummy of city scale (metropolitan) & $\begin{array}{l}0.1966 \\
(0.013)\end{array}$ & $* * *$ \\
\hline a dummy of city scale (large) & $\begin{array}{c}0.1077 \\
(0.0104)\end{array}$ & $* * *$ \\
\hline a dummy of city scale (medium) & $\begin{array}{c}0.0625 \\
(0.0109)\end{array}$ & *** \\
\hline a dummy of city scale (small) & $\begin{array}{r}0.0296 \\
(0.0143)\end{array}$ & $* *$ \\
\hline constant term & $\begin{array}{r}9.4321 \\
(0.1313) \\
\end{array}$ & $* * *$ \\
\hline$\overline{\text { F-statistics (all the coefficients }=0 \text { ) }}$ & 318.24 & t \\
\hline
\end{tabular}

Notes

1. The number of observations is 15,262 for the 1998 SLC and 15,542 for the 2001 SLC.

2. *,**, *** indicates $10 \%, 5 \%$, and $1 \%$ significance levels respectively

3. The number in a parenthesis is a standard error. Murphy and Topel's (1985) adjustment is employed in the right-hand panel.

4. The dummy is set 1 if a household has a member who has at least four disabled activities. 


\section{Table 4: Estimation Results with a Dummy for Being Bedridden}

Panel A: the 1998 SLC

\begin{tabular}{|c|c|c|}
\hline \multicolumn{3}{|c|}{ Dependent Variable: log of disposable household income } \\
\hline a dummy of disabled household members & $\begin{array}{c}-0.0898 \\
(0.0553)\end{array}$ & \\
\hline the number of household members & $\begin{array}{c}0.3401 \\
(0.0206)\end{array}$ & $* * *$ \\
\hline the age of a household head & $\begin{array}{r}0.0285 \\
(0.0021)\end{array}$ & $* * *$ \\
\hline a dummy of a male head & $\begin{array}{r}0.2866 \\
(0.0196)\end{array}$ & $* * *$ \\
\hline a dummy of a married head & $\begin{array}{c}0.1290 \\
(0.0196)\end{array}$ & $* * *$ \\
\hline the household share of children & $\begin{array}{c}-0.3284 \\
(0.0347)\end{array}$ & $* * *$ \\
\hline the houshold share of parents & $\begin{array}{c}0.1179 \\
(0.0457)\end{array}$ & $* * *$ \\
\hline a dummy of persons in nursing facilities & $\begin{array}{l}-0.0425 \\
(0.0797)\end{array}$ & \\
\hline a dummy of firm scale (medium) & $\begin{array}{c}0.1624 \\
(0.0107)\end{array}$ & $* * *$ \\
\hline a dummy of firm scale (large) & $\begin{array}{c}0.3663 \\
(0.0093)\end{array}$ & *** \\
\hline a dummy of firm scale (government) & $\begin{array}{c}-0.2663 \\
(0.0298)\end{array}$ & $* * *$ \\
\hline a dummy of city scale (metropolitan) & $\begin{array}{c}0.0243 \\
(0.0159)\end{array}$ & \\
\hline a dummy of city scale (large) & $\begin{array}{c}0.0426 \\
(0.0120)\end{array}$ & $* * *$ \\
\hline a dummy of city scale (medium) & $\begin{array}{c}0.0199 \\
(0.0123)\end{array}$ & \\
\hline a dummy of city scale (small) & $\begin{array}{l}-0.0096 \\
(0.0201)\end{array}$ & \\
\hline the squared age of a household head & $\begin{array}{l}-0.0002 \\
(0.0000)\end{array}$ & $* * *$ \\
\hline the number of workers & $\begin{array}{r}0.1133 \\
(0.0065)\end{array}$ & $* * *$ \\
\hline constant term & $\begin{array}{c}4.0709 \\
(0.0683)\end{array}$ & $* * *$ \\
\hline $\begin{array}{l}\text { R-squared } \\
\text { F-statistics (all the coefficieints }=0 \text { ) }\end{array}$ & $\begin{array}{c}0.4184 \\
165.13\end{array}$ & $* * *$ \\
\hline
\end{tabular}

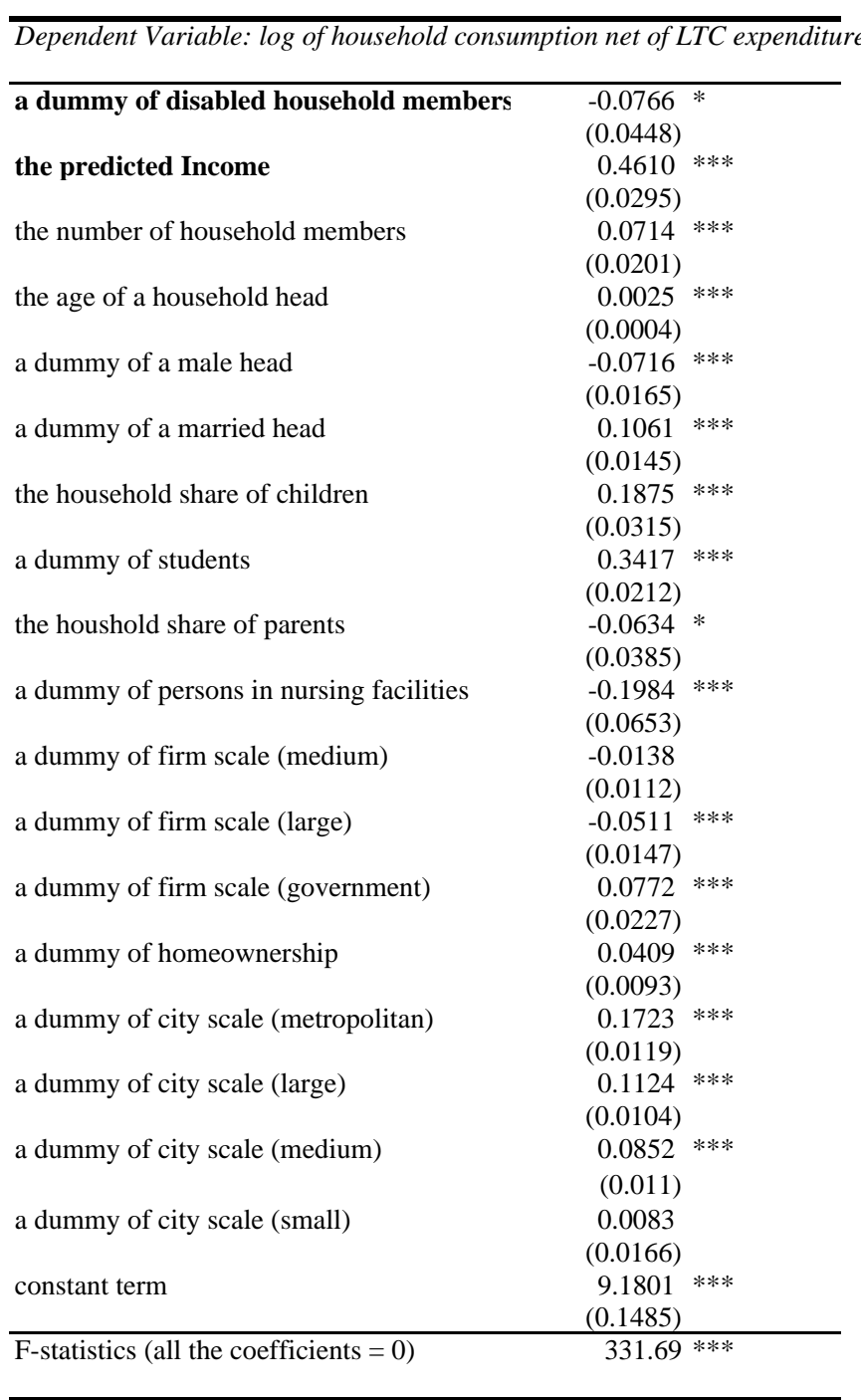


Panel B: the 2001 SLC

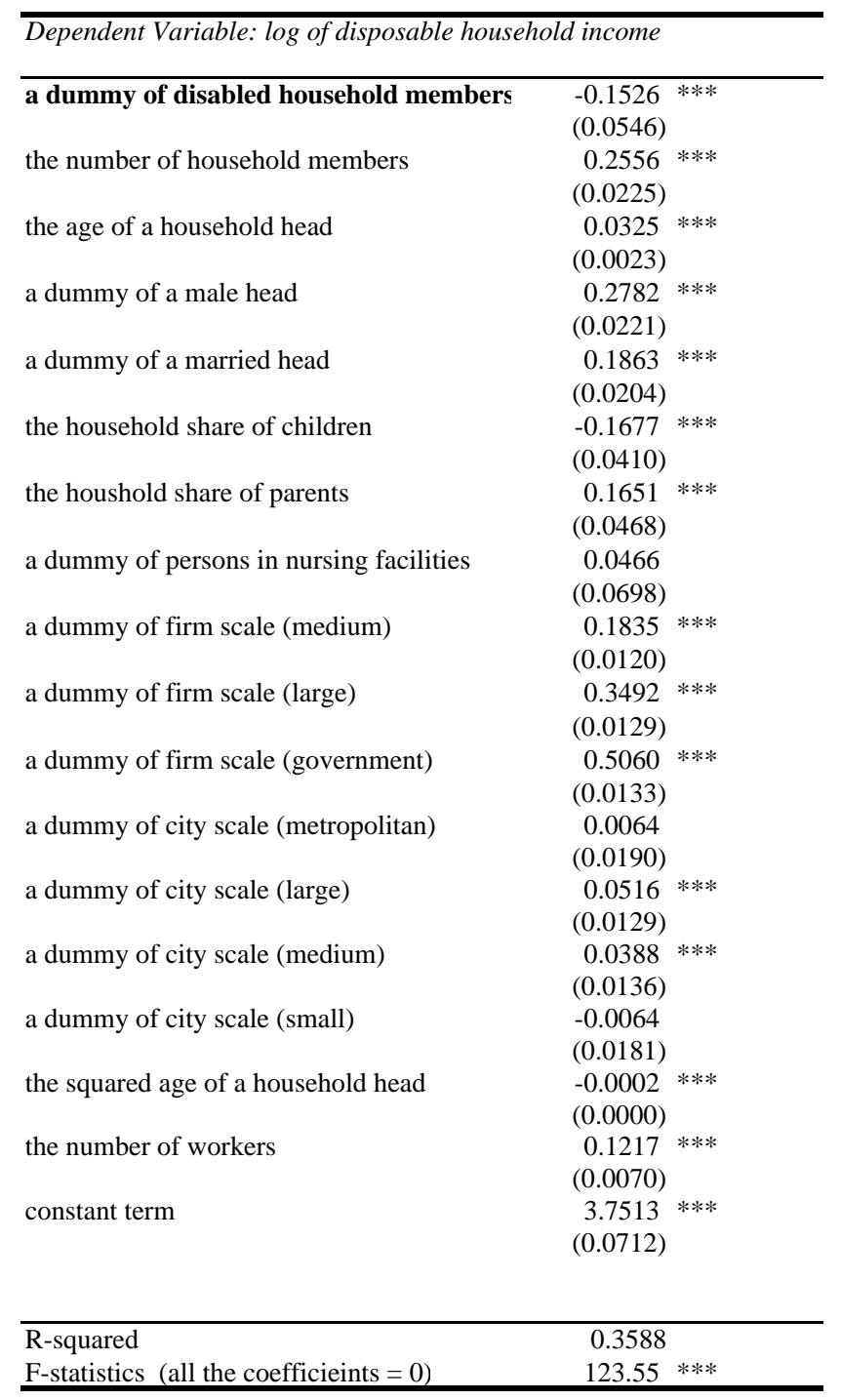

\begin{tabular}{|c|c|}
\hline a dummy of disabled household members & $\begin{array}{c}0.0450 \\
(0.0387)\end{array}$ \\
\hline the predicted Income & $\begin{array}{c}0.4169 \\
(0.0269)\end{array}$ \\
\hline the number of household members & $\begin{array}{c}0.1080 \\
(0.0181)\end{array}$ \\
\hline the age of a household head & $\begin{array}{c}0.0016 \\
(0.0004)\end{array}$ \\
\hline a dummy of a male head & $\begin{array}{l}-0.0538 \\
(0.0166)\end{array}$ \\
\hline a dummy of a married head & $\begin{array}{c}0.0982 \\
(0.0152)\end{array}$ \\
\hline the household share of children & $\begin{array}{l}0.1427 \\
(0.0302)\end{array}$ \\
\hline a dummy of students & $\begin{array}{l}0.3383 \\
(0.0199)\end{array}$ \\
\hline the houshold share of parents & $\begin{array}{c}0.0546 \\
(0.0347)\end{array}$ \\
\hline a dummy of persons in nursing facilities & $\begin{array}{c}0.0211 \\
(0.0484)\end{array}$ \\
\hline a dummy of firm scale (medium) & $\begin{array}{l}-0.0229)^{* *} \\
(0.0118)\end{array}$ \\
\hline a dummy of firm scale (large) & $\begin{array}{l}-0.0386 \quad * * * \\
(0.0154)\end{array}$ \\
\hline a dummy of firm scale (government) & $\begin{array}{l}-0.0711 \text { *** } \\
(0.0188)\end{array}$ \\
\hline a dummy of homeownership & $\begin{array}{c}0.0800 \\
(0.0105)\end{array}$ \\
\hline a dummy of city scale (metropolitan) & $\begin{array}{l}0.1967 \text { *** } \\
(0.013)\end{array}$ \\
\hline a dummy of city scale (large) & $\begin{array}{l}0.1078 \text { *** } \\
(0.0104)\end{array}$ \\
\hline a dummy of city scale (medium) & $\begin{array}{l}0.0625 \text { *** } \\
(0.0109)\end{array}$ \\
\hline a dummy of city scale (small) & ${ }_{0.0296}^{* *}$ \\
\hline constant term & $\begin{array}{c}9.4371 \\
(0.1297)\end{array}$ \\
\hline 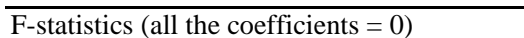 & $317.67 * * *$ \\
\hline
\end{tabular}

Notes

1. The number of observations is 15,262 for the 1998 SLC and 15,542 for the 2001 SLC.

2. *, **, *** indicates $10 \%, 5 \%$, and $1 \%$ significance levels respectively.

3. The number in a parenthesis is a standard error. Murphy and Topel's (1985) adjustment is employed in the right-hand panel.

4. The dummy is set 1 if a household has a bedridden member 